\title{
UJI PENETRASI SPESIMEN PADA SUNGKUP HELM BERBAHAN BIOKOMPOSIT SEBAGAI BAHAN ALTERNATIF PENGGANTI HELM
}

\author{
Boy Rollastin ${ }^{1}$ \\ ${ }^{1}$ Jurusan Teknik Mesin - Politeknik Manufaktur Negeri Bangka Belitung \\ Kawasan Industri Airkantung Sungailiat-Bangka, 33211 \\ Telp.0717-93586, Fax.0717-93585, b.rollastin@gmail.com
}

\begin{abstract}
The correct function of helmets is to protect motorcycle riders from head injuries during accident and head collision. Most of helmets existing in markets are produced by helmet factories. The price of used materials is quite high because those materials are still imported from overseas. It causes the increasing of helmet production cost and the helmet prices in the market become quite expensive. This research aims to find how a biocomposite material (85\% PP, $10 \%$ husk of rice and $5 \%$ MAPP) can be used as an alternative replacement material for helmet lid preparation on the condition of passing the SNI standar test, namely the penetration test. The testing process is carried out by using the test tools referring to SNI 181-2007. The results of penetration test with thickness of $4 \mathrm{~mm}$ showed that the speciment can not be penetrated by indenter in accordance with the requirements of SNI 1811-2007. So that the testing can be used as a reference for alternative materials to make a standard helmet lid.
\end{abstract}

Keywords: Biocomposite, lid model, finite element software, SNI 181-2007

\begin{abstract}
Abstrak
Fungsi helm yang benar adalah sebagai pelindung untuk keselamatan pengendara sepeda motor dari cedera kepala saat terjadi kecelakaan dan mengalami benturan kepala. Kebanyakan helm yang ada dipasaran buatan dari pabrik yang sudah berstandar, mulai dari penggunaan material pembuatan sungkup helm hingga proses pengujian pada helm itu sendiri. Penelitian ini bertujuan untuk mengetahui bagaimana suatu material biokomposit (85\% PP, 10\% sekam padi dan 5\% MAPP) dapat dijadikan sebagai material pengganti alternatif pembutan sungkup helm dengan syarat lulus pengujian yang ber-standar SNI yaitu uji penentrasi. Proses pengujian dilakukan dengan mengunakan alat uji yang mengacu pada SNI 181-2007. Hasil pengujian UJI penetrasi dengan ketebalan $4 \mathrm{~mm}$ tidak tertembus oleh indentor. sesuai dengan syarat SNI 1811-2007. Sehingga pengujian bisa dijadikan acuan untuk material alternatif pembuatan sungkup helm yang berstandar.
\end{abstract}

Kata kunci: Biokomposit, Spesimen, uji penentrasi, SNI 181-2007

\section{PENDAHULUAN}

Helm merupakan perlengkapan kendaraan bermotor berbentuk topi yang melindungi kepala apabila terjadi benturan. Beberapa bagian helm diantaranya tempurung, lapisan pelindung, pelindung muka, tali pengaman dll seperti terlihat pada gambar 1 . Salah satu bagian paling penting adalah bagian sungkup sebagai pelindung utama kepala ketika terjadi benturan. Sungkup helm terbuat dari material yang kuat dan bukan logam, tidak mudah berubah bentuk dan tahan terhadap pengaruh bahan pembersih. Selain itu helm harus lolos uji impact dan uji penetrasi. Uji impact yaitu pengujian helm dengan cara helm dijatuhkan dengan kecepatan maksimal $6.5 \mathrm{~m} / \mathrm{s}$ dan tidak terdapat kerusakan sedangkan Uji penetrasi yaitu pengujian dengan menggunakan alat pemberat berbentuk kerucut berbahan logam yang dikeraskan kemudian dijatuhkan dari ketinggian maksimal $1.6 \mathrm{~m}$ dan helm tidak terjadi kerusakan. 
1. Sungkup

2. Lapisan pelindung

3. Tali pemegang

4. Lapisan kenyamanan

5. pelindung telinga

6. kaitan kaca

7. Jaring helm

8. $\operatorname{Rim}$

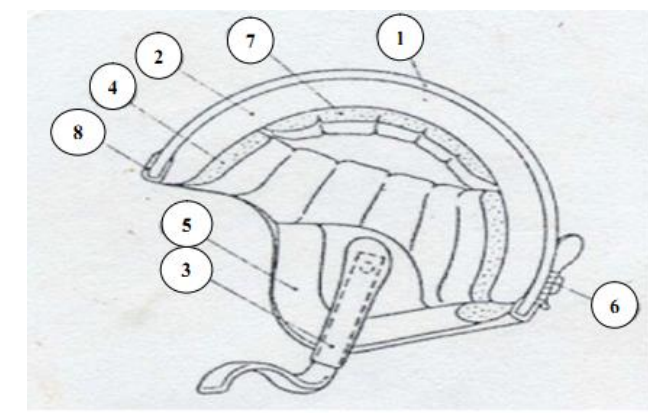

Gambar 1. Jenis konstruksi helm terbuka (open face) standar SNI

Berbagai pengujian Helm telah dilakukan beberapa peneliti, Diantranya : pengujian terhadap kualitas dan kekuatan helm dengan beberapa aspek yang berbeda, antara lain: uji standard keparahan rusak helm yang memungkinkan merusak lapisan kulit kepala lewat penetrasi [1], dengan melakukan pengujian tentang kekuatan dan ketahanan helm industri terhadap beban transversal. Dalam penelitian secara umum, Penelitian helm industry juga diuji dengan melakukan simulasi pada komputer dengan menggunakan pendekatan elemen hingga [2]. Namun ada juga penelitian yang meneliti tentang perilaku yang terjadi pada helm akibat benda jatuh dan ketinggian 40 meter [3]. Sedangkan untuk pengujian tentang kekuatan dan ketahanan helm industri terhadap beban dilakukan pengujian terhadap kekuatan dan ketahanan helm dengan impak terpusat dan penetrasi [4]. Dari penenlitian-penelitian yang telah dilakukan, hasilnya memberikan gambaran bagaimana kondisi helm setelah terkena beban dan dapat mengilustrasikan kondisi jika helm dipakai saat terjadi kecelakaan lalu lintas.

\subsection{Uji penetrasi}

Uji penetrasi adalah salah satu pengujian yang harus dilakukan, karena menjadi salah satu disyaratkan agar produk dinyatakan lulus dan bersetandar. Dengan tujuan agar dapat melindungi keselamatan pengendara roda dua terutama pada bagian kepala saat terjadi kecelakaan di jalan raya. Pengujian bertujuan untuk mengetahui sifat mekanis dari material yang digunakanpengujian ini menggunakan alat pemberat berbentuk kerucut berbahan logam yang dikeraskan kemudian dijatuhkan dari ketinggian maksimal 1,6 m, dan helm tidak terjadi kerusakan. Pemukul tidak boleh terjadi kontak (tembus) dengan blok uji pada setiap titik paling atas helm hingga kebatas perputaran helm pada blok uji.

\subsection{Prinsip}

Paku pemukul diajtuhkan ke arah bagian atas dari helm. Jika paku pemukul menembus kepala bagian dalam, maka helm dinyatakan tidak sesuai.

\subsection{Peralatan}

Balok uji setengah lingkaran yang terbuat dan kayu keras dengan logam lunak dimasukkan pada puncak sumbu pusat yang dipasang pada suatu landasan keras. Tali pengikat disediakan untuk mengamankan helm. Pada posisi paku pemukul dipasang, posisi di bawahnya sedemikian rupa sehingga paku pemukul dapat dijatuhkan dengan sedikit gesekan pada jatuhan tertentu ke atas pusat logam lunak seperti terlihat pada gamabr 2.5 di bawah in. Paku pemukul yang digunakan memiliki spesifikasi sebagai berikut: 
- Berat $3,0 \mathrm{~kg}{ }_{-0}^{+45}$ gram.

- Sudut titik radius kepala pemukul $60^{\circ} \pm 0,5^{\circ}$;

- Jari-jari bagian titik kepala pemukul 0,5 $\mathrm{mm} \pm 0,1 \mathrm{~mm}$;

- $\quad$ Tinggi minimum kerucut $40 \mathrm{~mm}$;

- Kekerasan 50 - 45 rockwell - C

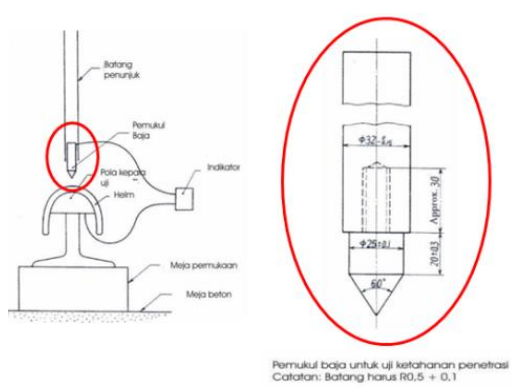

Gambar 2. Komponen Uji Penetrasi

\section{METODE PENELITIAN}

Tahapan penelitian dilakukan sesuai dengan diagram alir penelitian. Dimana pada penelitian ini akan dilakuakan langkah-langkah berdasarkan seperti yang dijelasakan pada gambar 2 dengan tahapantahapan sebagai berikut :

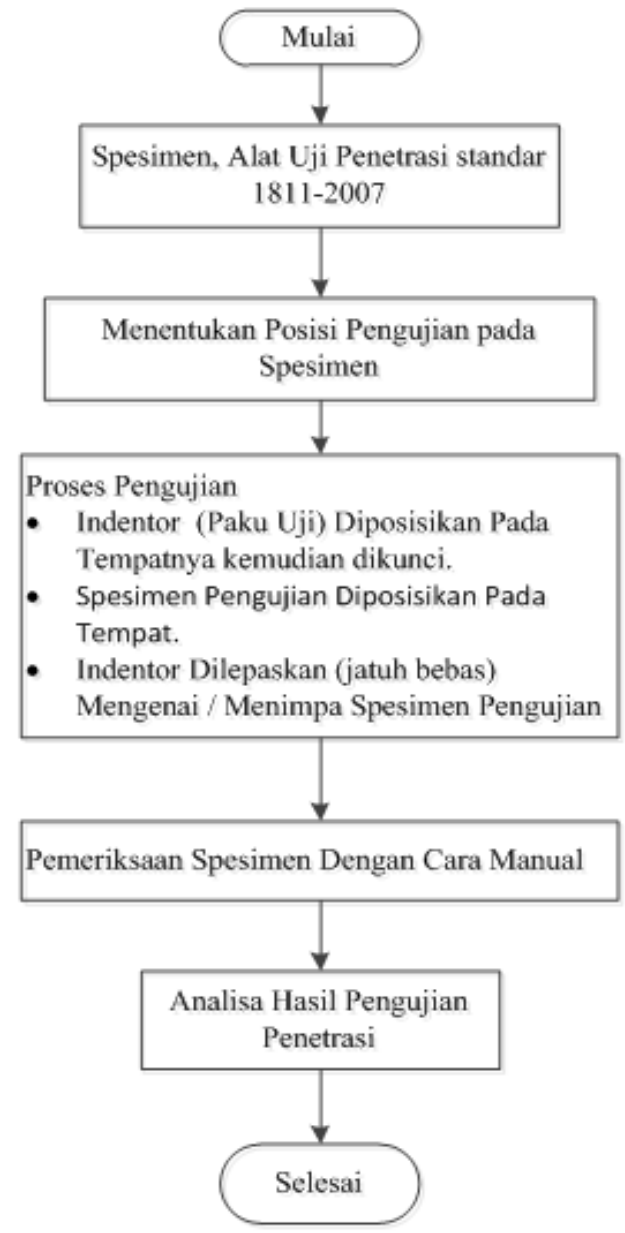

Gambar 3. Diagram alir pengujian penetrasi spesimen 


\section{Pembuatan Spesimen Uji Penetrasi Dengan Cara Injeksi}

Untuk mengevaluasi kekuatan terhadap penetrasi, dibuat spesimen dari material biokoposit dan PP. Hal ini dimaksudkan untuk membandingkan material biokomposit dengan material PP. Pembuatan Spesimen tebal 3,5 mm; $4 \mathrm{~mm}$ dan $5 \mathrm{~mm}$ dilakukan dengan cara sistem injeksi.

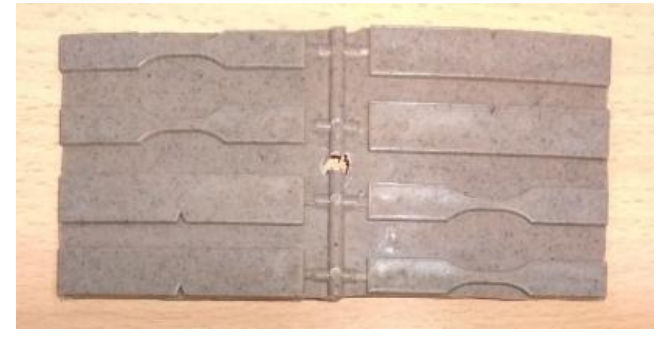

(a)

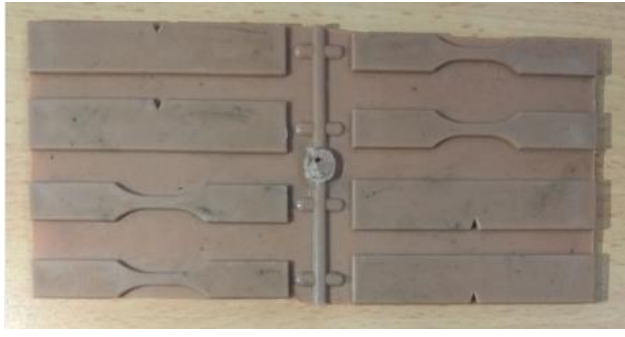

(b)

Gambar 4. Spesimen Pengujian Penetrasi (a) Material biokomposit tebal 3,5 mm () Material PP tebal 3,5 $\mathrm{mm}$

\subsection{Pengujian Spesimen Penetrasi Material Biokomposit dan PP}

Pada eksperimen ini dilakukan pengujian dengan dua jenis material yang berbeda, yaitu material Biokomposit sebagai bahan dalam penelitian, dan material Polypropylene (PP) sebagai material pembanding standar yang banyak digunakan dalam pembuatan helm di pasaran.

\subsection{Prosedur Pengujian}

Langkah -Langkah Pengujian yang dilakukan pada penelitian :

1. Memasang indentor (paku pemukul) pada bushing dan menguncinya, serta mengatur ketinggian indentor.

2. Memasang spesimen pada clam, dan mengunci dengan cara memutar poros pengencang, sehingga spesimen benar-benar terikat dan tidak bergerak saat pengujian.

3. Tarik pengunci indentor, indentor akan jatuh bebas ke bawah dan mengenai spesimen, sehingga melukai atau menembus spesimen.

4. Naikan kembali indentor pada posisinya ke atas, kemudian buka pengunci spesimen.

5. Periksa dan ukur hasil pengujian penetrasi tersebut, lalu input data pada tabel pengujian.

6. Untuk mengulangi pengujian, lakukan cara yang sama seperti diatas.

\section{HASIL DAN PEMBAHASAN}

Spesimen pada pengujian ini berasal dari dua material yang berbeda, yaitu material biokomposit dan material PP sebagai bahan untuk pembanding. Sebagai acuanya dari penelitian terdahulu yaitu dengan hasil uji tarik sebesar 30,77 Mpa. Pada eksperimen ini dilakukan 3 kali pengujian dengan ketebalan yang berbeda, dan masing-masing pengujian dan pengukuran tersebut dilakukan percoban sebanyak 3 kali. Setelah dilakukan pengujian pada spesimen, maka dilakukan dengan pengukuran diameter penetrasi dan mencari kedalaman penetrasi. Cara yang dilakukan dengan cara mengukur diameter hasil uji penetrasi dan mengukur serta menghitung kedalaman hasil uji penetrasi dengan rumus :

Dimana :

$$
h_{2}=\frac{d / 2}{\tan (\alpha / 2)} \text {. }
$$

Vol penetrasi = Volume luka saat penetrasi

h2 $\quad=$ Kedalaman luka penetrasi atau tingi kerucut

$\phi d \quad=$ Diameter luka hasil penetrasi

Gambar 5. Hasil Penetrasi

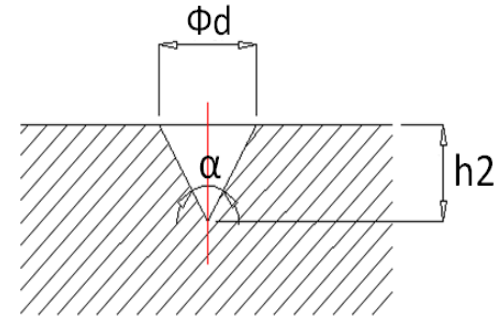




\section{Pemeriksaan Hasil Pengujian Spesimen}

Adapun alat uji penetrasi dan hasil pengujian spesimen yang sudah dilakukan seperti terlihat pada gambar 6 dibawah ini.

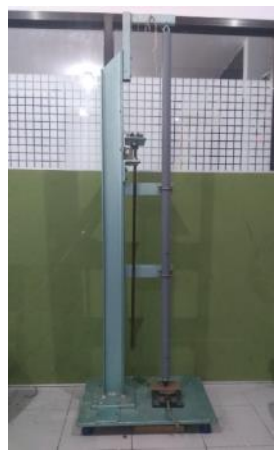

(a)

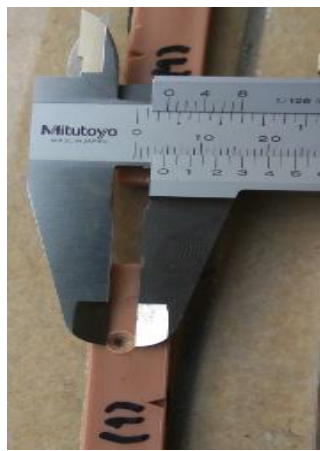

(b)

Gambar 6. Pengukuran diameter uji penetrasi

Pada proses uji penetrasi, apabila indentor yang dijatuhkan dengan bebas menembus spesimen dengan hasil diasumsikan seperti gambar 7 a), maka dianggap gagal (tidak lulus uji). Namun apabila indentor tersebut tidak menembus spesimen, maka dinyatakan lulus uji seperti yang di tunjukan pada gambar 7 b) dibawah ini.

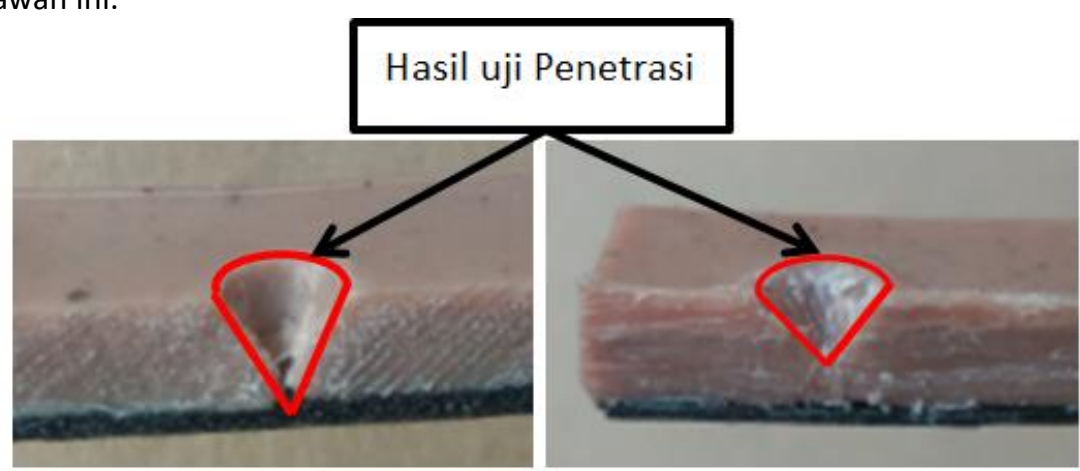

Gambar 7. a) Spesimen gagal pengujian, b) Spesimen lulus pengujian

\section{Hasil uji penetrasi Material Biokomposit}

Untuk menetukan gagal atau tidak hasil pemeriksaan spesimen dari uji penetrasi yang telah dilakukan dapat dilihat seperti yang terlihat pada tabel di bawah ini :

Tabel 1. Uji Penetrasi pada Spesimen Material Biokomposit tebal 3,5 mm

\begin{tabular}{cccccc}
\hline Kegiatan & Tebal & $\varnothing$ Penetrasi & $\begin{array}{c}\text { Kedalaman } \\
\text { Penetrasi } \\
(\mathrm{mm})\end{array}$ & $\begin{array}{c}\text { Jarak } \\
\text { Sisa } \\
(\mathrm{mm})\end{array}$ & Ket \\
\hline Percobaan ke1 & 3,5 & 4,5 & 3,897 & $-0,397$ & Gagal \\
Percobaan ke 2 & 3,5 & 4,6 & 3,984 & $-0,484$ & Gagal \\
Percobaan ke 3 & 3,5 & 4,5 & 3,897 & $-0,397$ & Gagal \\
\hline RATA - RATA & & 3,926 & $-0,426$ & Gagal \\
\hline
\end{tabular}

Tabel 2. Uji Penetrasi pada Spesimen Material Biokomposit tebal $4 \mathrm{~mm}$

\begin{tabular}{cccccc}
\hline Kegiatan & Tebal & $\emptyset$ Penetrasi & $\begin{array}{c}\text { Kedalaman } \\
\text { Penetrasi } \\
(\mathrm{mm})\end{array}$ & $\begin{array}{c}\text { Jarak } \\
\text { Sisa } \\
(\mathrm{mm})\end{array}$ & Ket \\
\hline Percobaan ke1 & 4 & 4,55 & 3,940 & 0,060 & Lulus \\
Percobaan ke 2 & 4 & 4,5 & 3,897 & 0,103 & Lulus
\end{tabular}




\begin{tabular}{rrrrrr} 
Percobaan ke 3 & 4 & 4,5 & 3,897 & 0,103 & Lulus \\
\hline RATA - RATA & & 3,912 & 0,088 & Lulus \\
\hline
\end{tabular}

Tabel 3. Uji Penetrasi pada Spesimen Material Biokomposit tebal $5 \mathrm{~mm}$

\begin{tabular}{cccccc}
\hline Kegiatan & Tebal & $\varnothing$ Penetrasi & $\begin{array}{c}\text { Kedalaman } \\
\text { Penetrasi } \\
(\mathrm{mm})\end{array}$ & $\begin{array}{c}\text { Jarak } \\
\text { Sisa } \\
(\mathrm{mm})\end{array}$ & Ket \\
\hline Percobaan ke1 & 5 & 4,5 & 3,897 & 1,103 & Lulus \\
Percobaan ke 2 & 5 & 4,4 & 3,811 & 1,189 & Lulus \\
Percobaan ke 3 & 5 & 4,5 & 3,897 & 1,103 & Lulus \\
\hline RATA - RATA & & 3,868 & 1,132 & Lulus \\
\hline
\end{tabular}

Hasil uji penetrasi Material PP

Hasil pengujian yang dilakukan dengan mengunakan material PP yang telah dilakukan ditunjukan seperti yang terlihat pada tabel di bawah ini :

Tabel 4. Uji Penetrasi pada Spesimen Material PP tebal 3,5 mm

\begin{tabular}{cccccc}
\hline Kegiatan & Tebal & $\boldsymbol{\varnothing \text { Penetrasi }}$ & $\begin{array}{c}\text { Kedalaman } \\
\text { Penetrasi } \\
(\mathrm{mm})\end{array}$ & $\begin{array}{c}\text { Jarak } \\
\text { Sisa } \\
(\mathrm{mm})\end{array}$ & Ket \\
\hline Percobaan ke1 & 3,5 & 4,5 & 3,897 & $-0,397$ & Gagal \\
Percobaan ke 2 & 3,5 & 4,55 & 3,940 & $-0,440$ & Gagal \\
Percobaan ke 3 & 3,5 & 4,5 & 3,897 & $-0,397$ & Gagal \\
\hline RATA - RATA & & 3,912 & $-0,412$ & Gagal \\
\hline
\end{tabular}

Tabel 5. Uji Penetrasi pada Spesimen Material PP tebal $4 \mathrm{~mm}$

\begin{tabular}{cccccc}
\hline Kegiatan & Tebal & $\varnothing$ Penetrasi & $\begin{array}{c}\text { Kedalaman } \\
\text { Penetrasi } \\
(\mathrm{mm})\end{array}$ & $\begin{array}{c}\text { Jarak } \\
\text { Sisa } \\
(\mathrm{mm})\end{array}$ & Ket \\
\hline Percobaan ke1 & 4 & 4,5 & 3,897 & 0,103 & Lulus \\
Percobaan ke 2 & 4 & 4,5 & 3,897 & 0,103 & Lulus \\
Percobaan ke 3 & 4 & 4,5 & 3,897 & 0,103 & Lulus \\
\hline \multicolumn{2}{r}{ RATA - RATA } & & 3,897 & 0,103 & Lulus \\
\hline
\end{tabular}

Tabel 6. Uji Penetrasi pada Spesimen Material PP tebal $5 \mathrm{~mm}$

\begin{tabular}{cccccc} 
& & $(\mathrm{mm})$ & $(\mathrm{mm})$ & $(\mathrm{mm})$ & \\
\hline Percobaan ke1 & 5 & 4,4 & 3,811 & 1,189 & Lulus \\
Percobaan ke 2 & 5 & 4,4 & 3,811 & 1,189 & Lulus \\
Percobaan ke 3 & 5 & 4,5 & 3,897 & 1,103 & Lulus \\
\hline RATA - RATA & & 3,839 & 1,161 & Lulus \\
\hline
\end{tabular}

Sebagai data pembanding hasil pengujian penetrasi dan pengukuran antara material biokomposit dan material pp dengan ketebalan spesimen yaitu $3,5 \mathrm{~mm} ; 4 \mathrm{~mm}$ dan $5 \mathrm{~mm}$ ditampilkan pada tabel 7 dibawah ini. 
Tabel 7. Pembanding Data Uji Penetrasi

\begin{tabular}{cccccc}
\hline $\mathbf{k e}$ & $(\mathrm{mm})$ & $\begin{array}{c}\varnothing \\
\text { Penetrasi } \\
(\mathrm{mm})\end{array}$ & $\begin{array}{c}\text { Kedalaman } \\
\text { penetrasi } \\
(\mathrm{mm})\end{array}$ & $\begin{array}{c}\varnothing \\
\text { Penetrasi } \\
(\mathrm{mm})\end{array}$ & $\begin{array}{c}\text { Kedalaman } \\
\text { penetrasi }(\mathrm{mm})\end{array}$ \\
\hline $\mathbf{1}$ & 3,5 & 4,5 & 3,897 & 4,5 & 3,897 \\
$\mathbf{2}$ & 4 & 4,6 & 3,984 & 4,55 & 3,940 \\
$\mathbf{3}$ & 5 & 4,5 & 3,897 & 4,5 & 3,897 \\
\hline $\mathbf{1}$ & 3,5 & 4,55 & 3,940 & 4,55 & 3,940 \\
$\mathbf{2}$ & 4 & 4,5 & 3,897 & 4,5 & 3,897 \\
$\mathbf{3}$ & 5 & 4,5 & 3,897 & 4,5 & 3,897 \\
\hline $\mathbf{1}$ & 3,5 & 4,4 & 3,897 & 4,4 & 0,314 \\
$\mathbf{2}$ & 4 & 4,4 & 3,811 & 4,4 & 0,314 \\
$\mathbf{3}$ & 5 & 4,5 & 3,897 & 4,5 & 0,321 \\
\hline
\end{tabular}

Dari hasil uji tabel diatas, spesimen tebal 3,5 $\mathrm{mm}$ mengunakan material biokomposit dan material PP, semua percobaan tidak lulus uji (gagal). Dikarenakan hasil dari uji penetrasi indentor (paku pemukul) menembus spesimen pengujian. Berbeda dengan pengujian dengan tebal $4 \mathrm{~mm}$ dan $5 \mathrm{~mm}$ dinyatakan lulus uji, karena hasil dari pengukuran uji penetrasi ini indentor tidak menembus dari material spesimen tersebut. Hal ini buktikan dengan adanya sisa tebal saat pengujian penetrasi. Spesimen material biokomposit tebal $4 \mathrm{~mm}$ dan $5 \mathrm{~mm}$ masing-masing sebesar 0,09 mm dan 1,14 mm. Sedangkan material PP dengan tebal $4 \mathrm{~mm}$ dan $5 \mathrm{~mm}$ masing-masing sebesar 0,15 mm dan 1,17 mm. Sehingga dapat disimpulkan bahwa material biokomposit dapat dipakai sebagai material alternatif pengganti PP untuk sungkup Helm dengan ketebalan $4 \mathrm{~mm}$.

\section{SIMPULAN}

Dari hasil uji penetrasi yang telah dilakukan bahawa pengujian uji penetrasi pada spesimen yang terdiri dari dua material yang berbeda dengan spesifikasi yang sama hasilnya tidak jauh berbeda, dimana spesimen dari bahan biokomposit dan PP dengan tebal material $4 \mathrm{~mm}$ dan $5 \mathrm{~mm}$ dinyatakan lulus uji penetrasi dikarenakan tidak tertembus indentor saat pengujian. Mempertimbangkan dari sisi harga, dan kekuatan yang hampir sama (mendekati) dengan material PP, maka material biokomposit ini layak direkomendasikan untuk menjadi material alternatif terbarukan pembuatan sungkup helm.

\section{DAFTAR PUSTAKA}

[1]. Standar Nasional Indonesia, Helm Pengendara Kendaraan Bermotor Roda Dua (SNI 1811-2007).

[2] Srikanth Pilla, Handbook of Bioplastics and Biocomposites Engineering Applications, USA: Scrivener Publishing, 2011.

[3]. Nayan, A,. Bustami syam, "Penyelidikan Mekanik Helmet Industri Akibat Beban Kecepatan Tinggi" Prosiding Seminar Material Dan Struktur (MASTRUCT), Medan, 2004.

[4]. McKeown, James, DOT Complince Testing, Friction Zone, 15-21, 2002.

[5]. Chia- Yuan Chang, "Devolopment Of a coupled Impact Model to Study of Motorcycle Helmet Protecting Effect", National Chung cheng University, Chiayi, Taiwan, Republic of China, 2000.

[6]. Mutawafiqin R., "Studi Eksperimental Variasi Komposisi Pelet Biokomposit (Polypropylene, Sekam Padi dan Maleic Anhydride PP) Terhadap Sifat Thermal \& Struktur Permukaan Sebagai Material Alternatif Produk Helm Standar", Surabaya, 2016. 